\title{
In silico modeling and characterization of phytoparasitic nematodes translationally- controlled tumor proteins
}

\author{
R.M. Moraes Filho ${ }^{1,3}$, A.F. Menezes ${ }^{1}$ and L.S.S. Martins ${ }^{2,3}$ \\ ${ }^{1}$ Departamento de Agronomia da Universidade Federal Rural de Pernambuco, \\ Recife, PE, Brasil \\ ${ }^{2}$ Departamento de Biologia, Universidade Federal Rural de Pernambuco, \\ Recife, PE, Brasil \\ ${ }^{3}$ Programa de Pós-Graduação em Agronomia/Melhoramento Genético de Plantas, \\ Universidade Federal Rural de Pernambuco, Recife, PE, Brasil \\ Corresponding author: R.M. Moraes Filho \\ E-mail: romulommfilho@yahoo.com.br
}

Genet. Mol. Res. 16 (3): gmr16039800

Received August 15, 2017

Accepted August 25, 2017

Published September 21, 2017

DOI http://dx.doi.org/10.4238/gmr16039800

Copyright $(2017$ The Authors. This is an open-access article distributed under the terms of the Creative Commons Attribution ShareAlike (CC BY-SA) 4.0 License.

\begin{abstract}
Plant parasitic nematodes infect a wide range of hosts representing the largest source of biotic stress experienced by plants. Meloidogyne genus comprises the most important parasitic nematodes, also known as root-knot nematodes. These parasitic organisms obtain nutrients to support their development through complex interactions with their hosts. The translationally-controlled tumor protein (TCTP) is widely expressed in eukaryotic organisms, and is related to a great diversity of biological processes such as calcium binding, cell proliferation and growth, pluripotency, regulation of apoptosis, microtubules stabilization, and histamine release. TCTP has been identified in the secretions of plant-parasitic nematodes, and may play a role in suppressing the plant immunity and programmed cell, hence promoting nematode parasitism. Our results revealed a high conservation
\end{abstract}

Genetics and Molecular Research 16 (3): gmr16039800 
of the evaluated protein sequences and little variation in their physicochemical characteristics, such as isoelectric points and hidropathicity. Phylogenetic analysis also revealed the presence of three main groups of TCTPs, corresponding to plant parasitic, animal parasitic and freeliving nematodes. Six plant parasitic TCTPs tertiary structure models were generated by homology modeling. The constructed models were highly similar and most of the structural variations occurred outside the characterized functional domains. To our knowledge, these are the first theoretical models of plant parasitic nematodes TCTPs and these results may provide a theoretical basis for future studies of host plant resistance to nematode infection.

Key words: Computational analysis; Parasitism resistance; Homology modeling

\section{INTRODUCTION}

The nematodes, or roundworms, are organisms adapted to a wide range of environmental conditions. Most nematodes are free-living, but a great number of them are parasites of animals and plants. Plant parasitic nematodes, or phytonematodes, represent the largest source of biotic stress experienced by plants and can cause stunting, early senescence, or even total crop loss. Almost all crop plants are parasited by at least one nematode species and the devastating rootknot nematodes (Meloidogyne spp) and cyst nematodes (Globodera spp, Heterodera spp) are the most important parasitic nematode group, causing billions of dollars of agricultural losses each year (Bird, 2004; Haegeman et al., 2009; Perry and Moens, 2011).

Nematode infection triggers complex changes in plant gene expression as they penetrate the roots of the host. They induce dramatic changes in the selected root vascular cells, forming elaborate feeding cells to permanently supply nutrients needed to their development to reproductive adults (Hussey et al., 2002). Phytonematodes all share a hollow needle-like structure that is used to withdraw nutrients of plant cells on which they feed. In addition to this, they secrete cell-wall degrading enzymes (CWDE) to allow migration through the plant root, and secretory effector proteins (SEP) to suppress host defense responses (Williamson and Gleason, 2003; Davis et al., 2004; Baum et al., 2007; Davis et al., 2008; Perry and Moens, 2011; Haegeman et al., 2012; Rai et al., 2015). In response to pathogen infection, plants can induce a hypersensitive reaction that causes a rapid death of cells surrounding the site of infection;thus, restricting the growth and spread of pathogens (Heath, 2000; Jones and Dangl, 2006; Chisholm et al., 2006; Zhuo et al., 2016). Ability to suppress this programmed cell death could be preponderant to successful parasitism in plant parasitic nematodes.

The translationally-controlled tumor protein (TCTP) is a highly conserved protein widely expressed in eukaryotic organisms. It is a multifunctional protein related to biological processes such as calcium binding, cell proliferation and growth, pluripotency, regulation of apoptosis, microtubules stabilization, and histamine release (Bommer and Thiele, 2004; Arcuri et al., 2004; Koziol and Gurdon, 2012). TCTP is related to interact with a large number of different proteins, however, its binding partners are not well conserved in eukaryotes, and therefore its alternative functions may differ from an organism to another (Wu et al., 2015). It was first identified in mice (Yenofsky et al., 1982) and humans (Gross et al., 1989), and then in

Genetics and Molecular Research 16 (3): gmr16039800 
other organisms such as yeasts, invertebrates and plants (Bonnet et al., 2000; Gnanasekar et al., 2002; Rao et al., 2002; Hoepflinger et al., 2013). TCTP has been identified in the secretions of animal-parasitic nematodes (Gnanasekar et al., 2002), and of Meloidogyne enterolobii, a plant parasitic nematode (Zhuo et al., 2016). Expressed specifically within the dorsal oesophageal gland, which produces SEPs, $M$. enterolobii TCTP may play a role in suppressing the plant immunity and programmed cell, hence promoting nematode parasitism (Zhuo et al., 2016).

Little is known about biological functions, structure and conservation of TCTP plant parasitic nematodes. Therefore, the aim of the present study was to characterize structurally and functionally, TCTP sequences from $M$. enterolobii and other phytoparasitic nematodes with bioinformatic methodologies, and develop tertiary structure models of these proteins. This study will provide valuable theoretical insights for TCTP functions and structure in plant parasitic nematodes that can be useful for future studies involving these proteins and host plant resistance to nematode infection.

\section{MATERIAL AND METHODS}

\section{Data retrieval from plant pathogenic, animal pathogenic, and free living nematodes}

MeTCTP sequence described by Zhuo et al. (2016) was used as query in the tool BLASTp from the National Center for Biotechnology Information (NCBI, http://www. ncbi.nlm.nih.gov) database. Sequences of animal and free-living nematodes with high similarity to the query were selected and their FASTA protein sequences were retrieved (Table 1). Additionally, we ran the BLASTp tool to search for protein homologues from the plant parasitic nematodes genomes in the wormbase database (parasite.wormbase.org). This database contains five publically available genomes of completely sequenced plant parasitic nematodes, Meloidogyne floridensis, Meloidogyne incognita, Meloidogyne hapla, Bursaphelenchus xylophilus, and Globodera pallida.

\section{Sequence analysis}

Physico-chemical parameters of phytonematodes TCTP sequences were analyzed by ProtParam (http://web.expasy.org/protparam) (Gasteiger et al., 2005). Subcellular localizations were predicted by the CELLO2GO server (Yu et al., 2014). The presence of signal peptide cleavage sites were investigated using the TOPCONS server (http://topcons. cbr.su.se/) (Tsirigos et al., 2015).

\section{Phylogenetic analysis}

Sequence alignment of TCTPs was performed with ClustalW algorithm implemented in Molecular Evolutionary Genetic Analysis (MEGA 6.06) (Tamura et al., 2011), with default parameters. The phylogenetic tree was constructed using the neighbor-joining method for 2000 bootstrap replicates.

\section{Protein-protein interactions}

STRING 9.1 database (Franceschini et al., 2013) (http://string-db.org/) was used 
to predict potential interacting proteins. The database contains information from numerous sources, including experimental repositories, computational prediction methods, and public text collections.

\section{Tertiary structure prediction, evaluation, and validation of the model}

3-D models of TCTPs were generated using the Phyre2 server (http://www.sbg.bio. ic.ac.uk/phyre2) (Kelley et al., 2015) in multi-template intensive mode and visualized by UCSF Chimera package (Pettersen et al., 2004). Model quality was evaluated using the Molprobity server (http://molprobity.biochem.duke.edu/) (Chen et al., 2010) by Ramachandran plot analysis. Z-score was calculated using interactive ProSA-web server (https://prosa.services. came.sbg.ac.at/prosa.php) to recognize errors in 3-D structures (Wiederstein and Sippl, 2007).

\section{RESULTS AND DISCUSSION}

In this study, we analyzed TCTP sequences from plant parasitic nematodes from the order Tylenchida and homologue sequences from animal parasitic and free-living nematodes. The protein sequences were retrieved in FASTA format from the NCBI database and from complete genomes of plant parasitic nematodes (Table 1).

Table 1. Fourteen evaluated TCTP sequences identifications and their species of origin.
\begin{tabular}{|l|l|l|l|l}
\hline Species & Identification & Family & Common name & Mode of life \\
\hline Bursaphelenchus xylophilus & BXY_0592900.1 & Aphelenchoididae & Pine wilt nematode & Plant parasitic \\
\hline Globodera pallida & GPLIN_000622600 & Heteroderidae & Cyst nematode & Plant parasitic \\
\hline Meloidogyne enterolobii & JN968577.1 & Meloidogynidae & Root-knot nematode & Plant parasitic \\
\hline Meloidogyne incognita & Minc02150 & Meloidogynidae & Southern Root-knot nematode & Plant parasitic \\
\hline Meloidogyne hapla & MhA1 Contig1983.frz3.gene9 & Meloidogynidae & Northern Root-knot nematode & Plant parasitic \\
\hline Meloidogyne floridensis & Scaf00174-processed-gene-0.5-mRNA-1 & Meloidogynidae & Root-knot nematode & Plant parasitic \\
\hline Brugia malayi & XP_001897741.1 & Onchocercidae & Agent of lymphatic filariasis & Animal parasitic \\
\hline Dirofilaria immitis & AGI74995.1 & Onchocercidae & Canine heartworm nematode & Animal parasitic \\
\hline Loa loa & EFO28099.2 & Onchocercidae & Eye worm & Animal parasitic \\
\hline Toxocara. canis & KHN75998.1 & Toxocaridae & Dog roundworm & Animal parasitic \\
\hline Caenorhabditis briggsae & XP_002639808.1 & Rhabditidae & Roundworm & Free living \\
\hline Caenorhabditis elegans & NP_492767.1 & Rhabditidae & Roundworm & Free living \\
\hline Caenorhabditis remanei & XP_003112086.1 & Rhabditidae & Roundworm & Free living \\
\hline Pristionchus pacificus & ABF69523.1 & Neodiplogasteridae & Roundworm & Free living \\
\hline
\end{tabular}

Physico-chemical properties of the TCTP protein sequences were deduced by the ProtParam server. Table 2 shows the molecular weight, theoretical isoelectric point (pI), and grand average of hydropathicity (GRAVY) of the evaluated protein sequences.

As shown in Table 2, plant parasitic TCTP sequences varied in size from 156 (M. hapla) to 186 (M. enterolobii) amino acids. The molecular weight varied from $17.78 \mathrm{kDa}$ (M. hapla) to $21.56 \mathrm{kDa}$ (M. enterolobii). The $\mathrm{pI}$ was between 4.67 (G. pallida) and 5.48 (M. hapla). The GRAVY was between -0.572 (M. enterolobii) and 0.402 (G. pallida). ProtParam analysis revealed proteins with very similar physico-chemical properties. All TCTP sequences were predicted to be hydrophilic. As seen in Table 2, the pI of the evaluated proteins was between 4.67 and 5.48 indicating their acidic character. The $\mathrm{pI}$ of a protein indicates the $\mathrm{pH}$ at which the protein is most unstable and is least soluble (Shaw et al., 2001).

TOPCONS server was used to predict post-translational modifications. This tool predicts the presence and location of signal peptide cleavage sites in protein sequences incorporating a prediction of cleavage sites and a signal peptide/non-signal peptide prediction

Genetics and Molecular Research 16 (3): gmr16039800 
based on a combination of several artificial neural networks. TOPCONS predicted that none of the evaluated sequences had an $\mathrm{N}$-terminal signal peptide, this fact was expected as demonstrated by other studies that TCTP is secreted by a non-classical pathway without the aid of signal peptides (Amzallag et al., 2004, Bommer and Thiele, 2004; Zhuo et al., 2016).

The analysis of subcellular location with the CELLO2GO server predicted that the evaluated TCTPs are intracellular proteins, being classified as cytoplasmatic or nuclear.

Table 2. Primary structure analisys and subcellular locations of the evaluated TCTP sequences.

\begin{tabular}{l|c|c|c|c|c|c}
\hline Origin species & Protein size & MW $(\mathrm{kDa})$ & $\mathrm{pI}$ & GRAVY & SPCS & ScL \\
\hline B. malayi & 181 & 20.766 & 4.62 & -0.485 & - & $\mathrm{Cy}, \mathrm{Nc}$ \\
\hline B. xylophilus & 181 & 20.622 & 4.71 & -0.501 & - & $\mathrm{Cy}, \mathrm{Nc}$ \\
\hline C. briggsae & 181 & 20.626 & 4.78 & -0.360 & - \\
\hline C. elegans & 181 & 20.542 & 4.78 & 0.370 & $\mathrm{Cy}$ \\
\hline C. remanei & 181 & 20.598 & 4.78 & -0.386 & - & $\mathrm{Cy}$ \\
\hline D. immitis & 181 & 20.739 & 4.62 & -0.425 & - & $\mathrm{Cy}$ \\
\hline G. pallida & 180 & 20.391 & 4.67 & -0.402 & - & $\mathrm{Cy}, \mathrm{Nc}$ \\
\hline L. loa & 187 & 21.398 & 4.69 & -0.452 & - & $\mathrm{Cy}$ \\
\hline M. enterolobii & 186 & 21.536 & 4.72 & -0.572 & - & $\mathrm{Cy}, \mathrm{Nc}$ \\
\hline M. floridensis & 173 & 19.780 & 4.74 & -0.498 & - & $\mathrm{Cy}$ \\
\hline M. hapla & 156 & 17.779 & 5.48 & -0.505 & - & $\mathrm{Cy}$ \\
\hline M. incognita & 179 & 20.584 & 4.75 & -0.445 & - & $\mathrm{Cy}, \mathrm{Nc}$ \\
\hline P. pacificus & 170 & 19.315 & 4.75 & -0.402 & - & $\mathrm{Cy}$ \\
\hline T. canis & 181 & 20.880 & 4.72 & -0.482 & - & $\mathrm{Cy}, \mathrm{Nc}$ \\
\hline
\end{tabular}

\section{Multiple alignment and phylogenetic analysis}

To examine the phylogenetic relationships of the evaluated TCTP sequences, a multiple alignment was performed by ClustalW algorithm implemented in the MEGA 6.06 software (Figure 1). The signature regions of TCTPs described by Bommer and Thiele (2004) and Microtubule binding sites (Gachet et al., 1999) are highlighted in the multiple alignment. All three regions are present in the 14 evaluated sequences and are highly conserved. A phylogenetic tree was constructed using the neighbor-joining (NJ) method and the bootstrap test carried out with 2000 replicates. For this analysis, animal parasitic and free-living nematodes were included in the alignment to evaluate the conservation of TCTPs in the phylum Nematoda. In the NJ tree, the evaluated TCTP sequences from 14 nematode species were divided into three groups by similarity (Figure 2). Plant parasitic and animal parasitic TCTPs showed more similarity to each other than to TCTPs from free living nematodes.

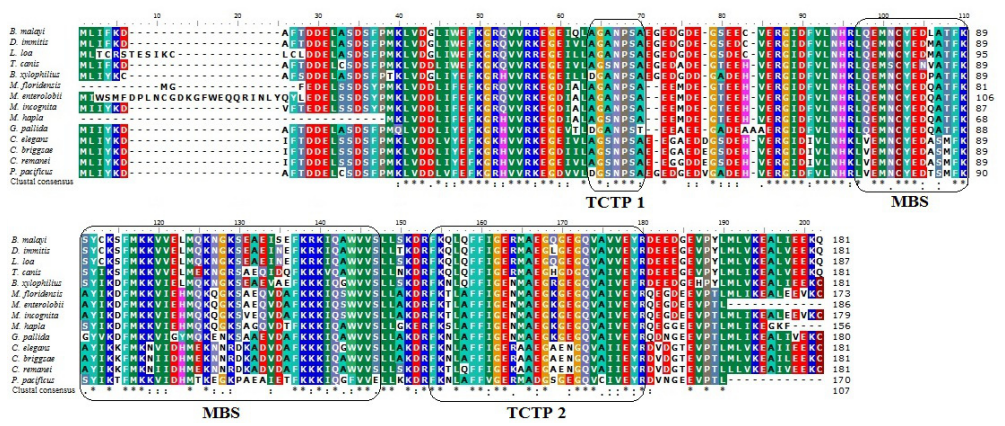

Figure 1. Sequence alignment nematodes TCTP proteins. Sequences were aligned by ClustalW, and identical and similar residues are displayed in the same color. Microtubule-binding sites (MBS) (Gachet et al., 1999) and TCTP 1 and TCTP2 signature sequences (Bommer and Thiele, 2004) are indicated below the sequences. 


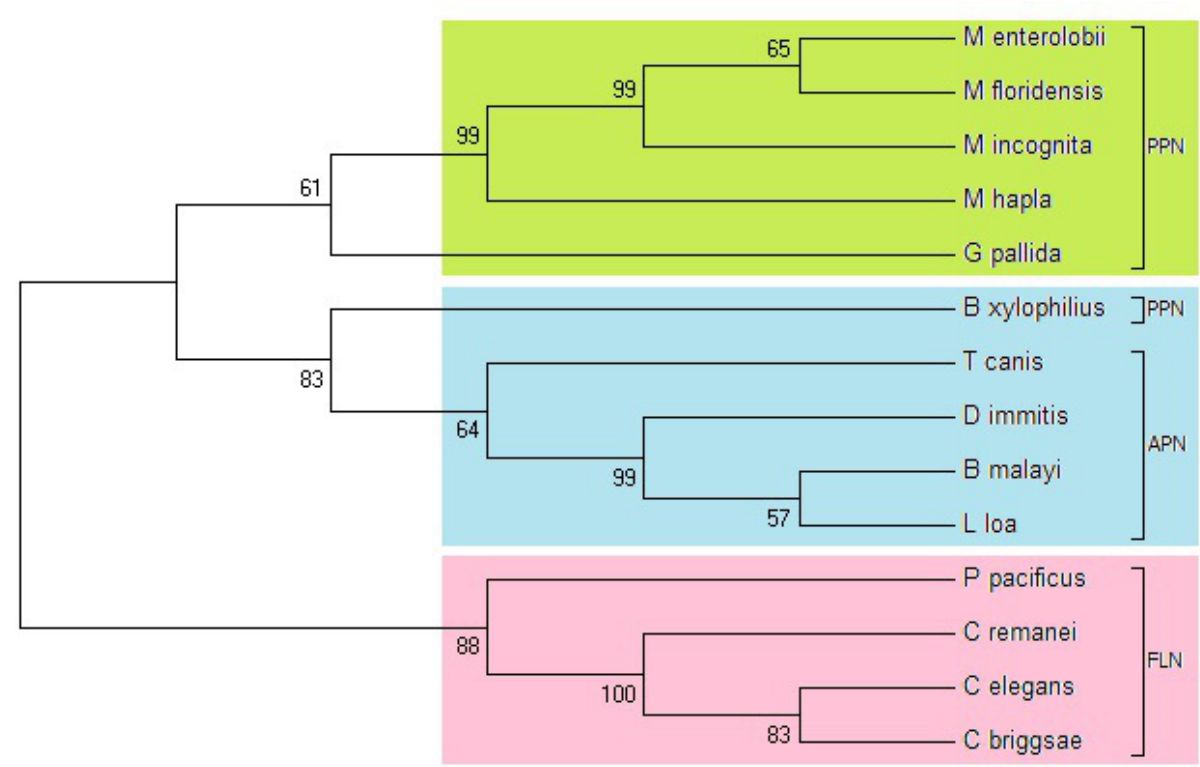

Figure 2. Neighbor-joining phylogenetic tree of plant parasitic (PPN), animal parasitic (APN), and free-living (FLN) nematodes TCTPs. The percentage of 2000 bootstrap replicate is given at each node. Based on the phylogenetic tree result, TCTP sequences were divided into three groups with different colors.

\section{Functional interaction network analysis}

In order to predict protein interactions of TCTPs, Caenorhabditis elegans TCTP was analyzed by the STRING 9.1 tool as the most similar representative of the MeTCTP in the software database. STRING is a database of known and predicted protein interactions.

STRING 9.1 revealed 20 putative interaction partners with score $>0.9$ for C. elegans TCTP (Figure 3a). Seventeen of these identified partners were ribosomal proteins, the other three were an elongation factor (eef-2) that catalyzes the GTP-dependent ribosomal translocation step during translation elongation, an ubiquitin (Ubq-2) and an hypothetical protein (Y37E3.8). STRING also showed TCTP co-expression patterns with these proteins (Figure 3b). Experimental evidences points that TCTP is co-regulated with ribosomal proteins (Brown et al., 2000; Langdon et al., 2004). TCTP was also described to bind an elongation factor, which is responsible for the transport of the aminoacyl tRNA to the ribosome during protein synthesis (Le Sourd et al., 2006; Sasikumar et al., 2012; Wu et al., 2015). STRING results suggest that TCTP and the identified functional partners are strongly correlated and likely in the same biological pathway.

\section{Tertiary structure prediction, evaluation and validation of the model}

The six plant parasitic TCTPs were selected for tertiary structure prediction by homology modeling. The model was constructed using the Phyre2 server. To produce a three dimensional model, Phyre2 uses the alignment of hidden Markov models via HHsearch (Söding, 2005) to improve the accuracy of alignment and detection rate, and incorporates

Genetics and Molecular Research 16 (3): gmr16039800 
an $a b$ initio folding simulation to model regions in the proteins with no detectable homology to known structures, the Poing tool (Jefferys et al., 2010). The methodology also combines multiple templates to improve model accuracy if necessary.
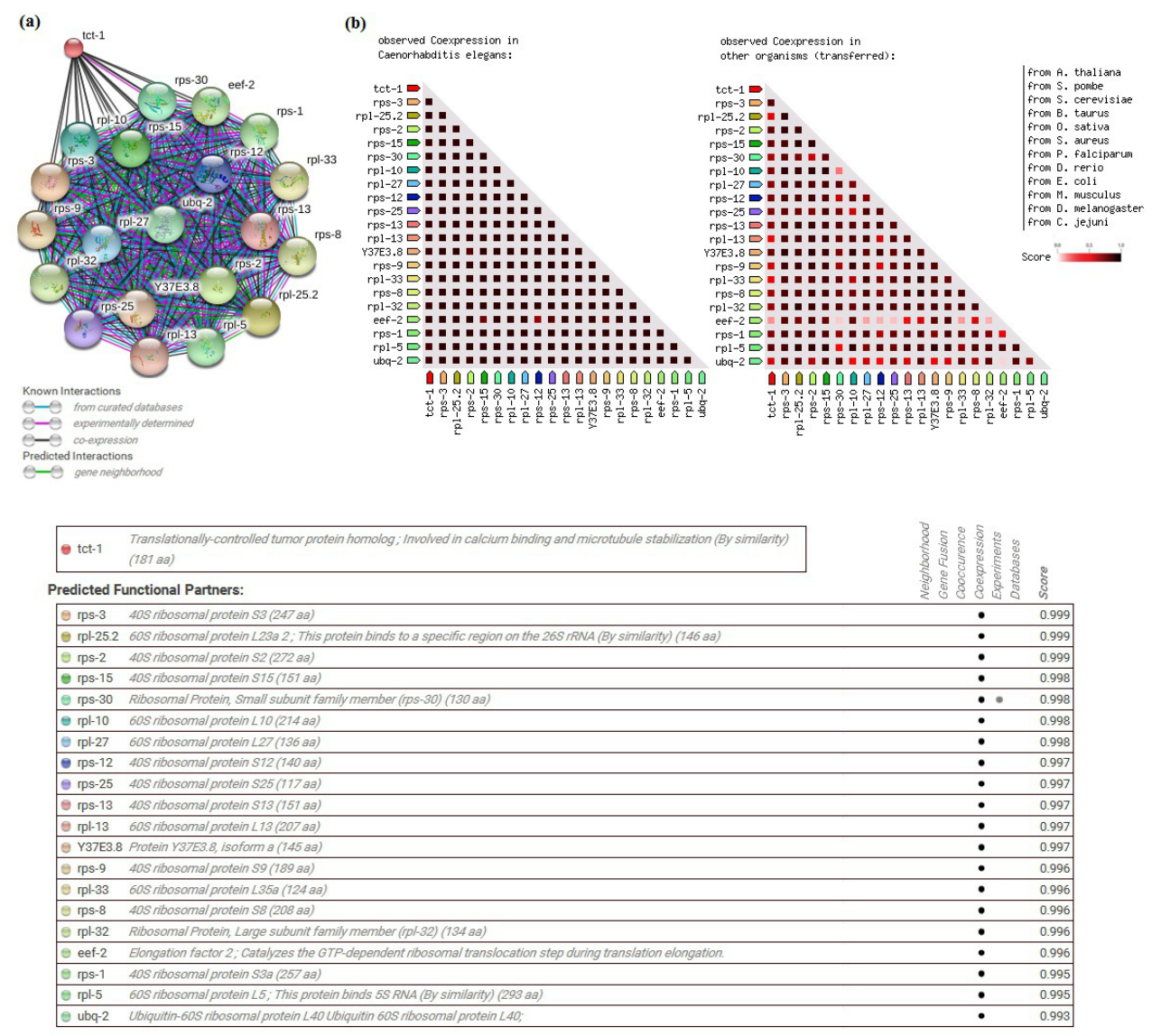

Figure 3. Protein-protein interactions predicted by the STRING 9.1 tool. a. Predicted Interactive network of Caenorhabditis elegans TCTP. b. Coexpression of C. elegans TCTP and other eukaryotic species: the intensity of color indicates the level of confidence that two proteins are functionally associated, given the overall expression data in the organism.

Figure 4 shows the six models of plant parasitic TCTPs generated. Colored regions are correspondent to the TCTP1, TCTP2 and MBS signature regions. Verification of stereochemical quality of the models using Ramachandran plot analysis was performed by the Molprobity server. ProSA-web (Protein Structure Analysis web) was used for error recognition in the tertiary structure prediction of the models. The Z-score was used to measure energy, as it indicated overall quality of the model. Positive Z-score values show that the structure is not stabilized while zero and negative scores represent one of the ideal structures. The generated models had $88.59 \%$ (M. enterolobii) to $94.16 \%$ (M. hapla) of amino acid residues were in Ramachandran plot analysis favored regions and Z-scores of -5.06 (B. xylophilius) to -3.90 (M. enterolobii) (Table 3). Due to the presence of Ramachandran outliers, model refinement

Genetics and Molecular Research 16 (3): gmr16039800 
was carried out with the KiNG software (Chen et al., 2009). MeTCTP validation results are showed in Figure 5. The plot of residue scores shows local model quality by plotting energies as a function of amino acid sequence position (Figure 5b). Positive values correspond to problematic or erroneous parts of the input structure. As was demonstrated in the graph of Figure 5c, most of amino acid residues of MeTCTP are below zero on x-axis.

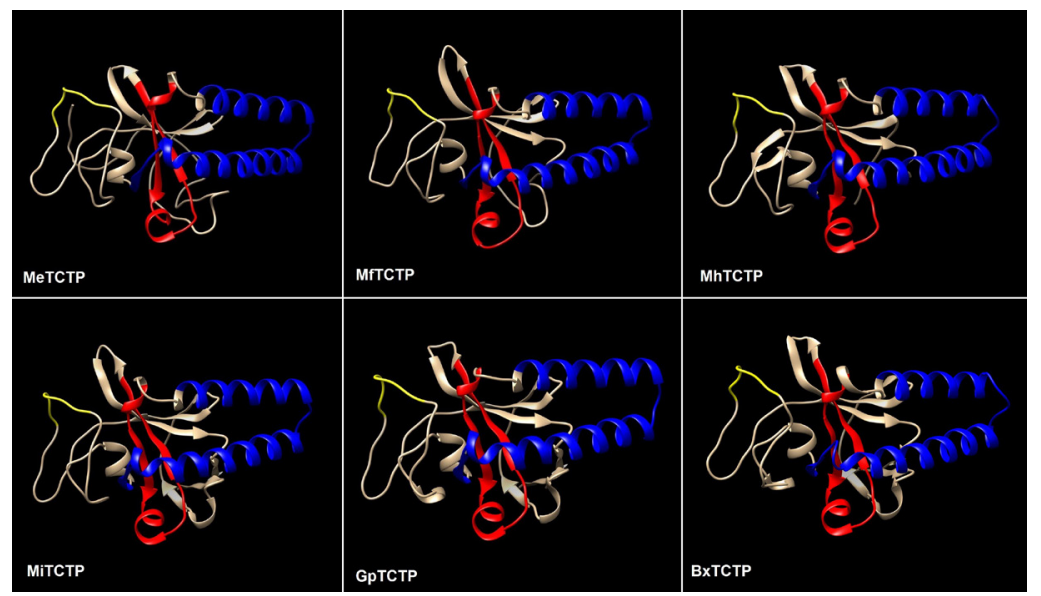

Figure 4. Tertiary structure prediction of phytonematodes TCTPs. Colored regions are correspondent to TCTP1 (yellow), MBS (blue) and TCTP2 (red).

Table 3. Modeling and validation results of phytonematodes TCTPs.

\begin{tabular}{l|c|c|c|c|c|c|c}
\hline Origin Species & PDB Models & Ab initio residues & Identity & Query coverage & Z-score & $\%$ RP & Outliers \\
\hline M. enterolobii & c2kwbA & 20 & $70 \%$ & $89 \%$ & $-3.90(-3.84)$ & $88.59 \%(96.74 \%)$ & $2.17 \%(0)$ \\
\hline M. floridensis & c2kwbA & 2 & $72 \%$ & $90 \%$ & $-4.56(-4.61)$ & $92.40 \%(97.66 \%)$ & $0.58 \%(0)$ \\
\hline M. hapla & c2kwbA & 1 & $71 \%$ & $99 \%$ & $-4.99(-4.91)$ & $94.16 \%(98.70 \%)$ & $1.30 \%(0)$ \\
\hline M incognita & $\mathrm{c} 2 \mathrm{kwbA}$ & 0 & $73 \%$ & $100 \%$ & $-5.01(-4.92)$ & $93.22 \%(98.87 \%)$ & $1.69 \%(0)$ \\
\hline B. xylophilius & $\mathrm{c} 2 \mathrm{kwbA}$ & 0 & $72 \%$ & $100 \%$ & $-5.06(-4.91)$ & $89.39 \%(98.32 \%)$ & $2.79 \%(0)$ \\
\hline G pallida & $\mathrm{c} 2 \mathrm{kwbA}$ & 0 & $72 \%$ & $100 \%$ & $-4.68(-4.67)$ & $89.33 \%(97.75 \%)$ & $2.81 \%(0)$ \\
\hline
\end{tabular}

The six models have highly similar structures and variations occurred mostly outside the TCTP1, TCTP2 and MBS regions. Figure 6a shows the surface area of the MeTCTP and the location of the signature regions. Hydrophobicity generated by the UCSF Chimera software as can be seen in Figure 6b, confirms the hydrophilic character of TCTP. The electrostatic surface (Figure 6c) shows a mostly negatively charged surface for MeTCTP.

Knowledge on protein three-dimensional structures is of great importance to understand its functions and molecular interactions. Homology modeling methodologies compares a given sequence with proteins with known tertiary structure to construct a theoretical model. Bioinformatics analysis, can play a vital role in the interpretation of proteomic data. These methodologies have been extensively used for predicting function and structure of proteins from its amino acid sequences (Darabi and Seddigh, 2015; Vatansever et al., 2015; Moraes Filho and Martins, 2016). In this study, we present the first tertiary models of TCTPs from Meloidogyne enterolobii and correlated plant parasitic species obtained from public databases. These findings can provide useful information on the molecular basis of the functions of these proteins and the understanding of nematode infection processes. 

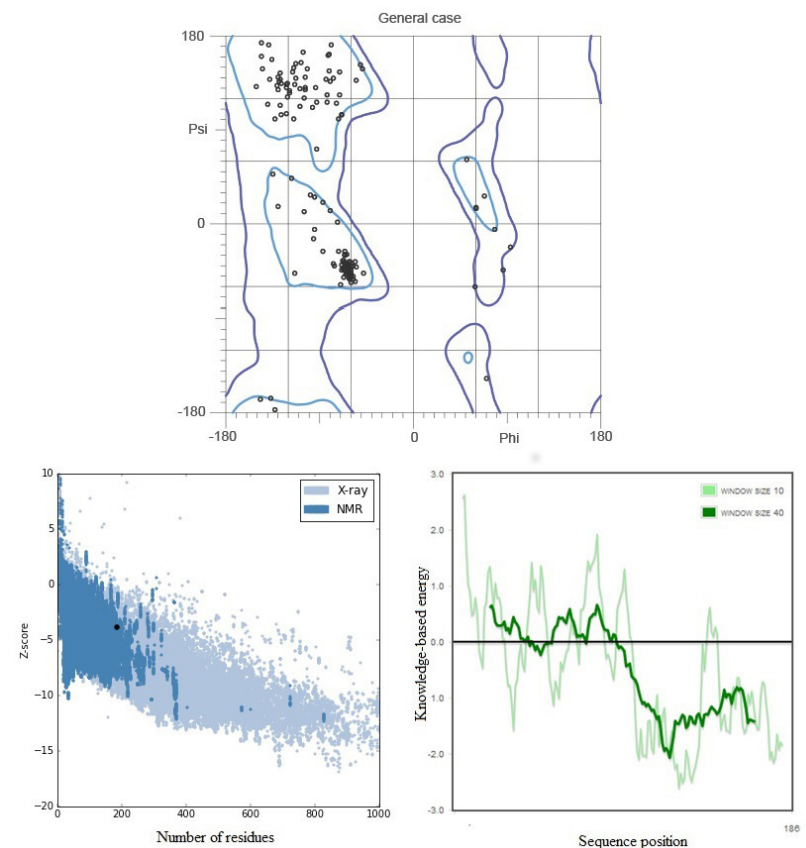

Figure 5. a. Ramachandran plot of MeTCTP generated by the MOLPROBITY server. b. ProSA-web Z-score plot of MeTCTP showing the $Z$ value (black dot) and c. ProSA-web plot of MeTCTP showing the energy graph of residue scores of a native protein structure.

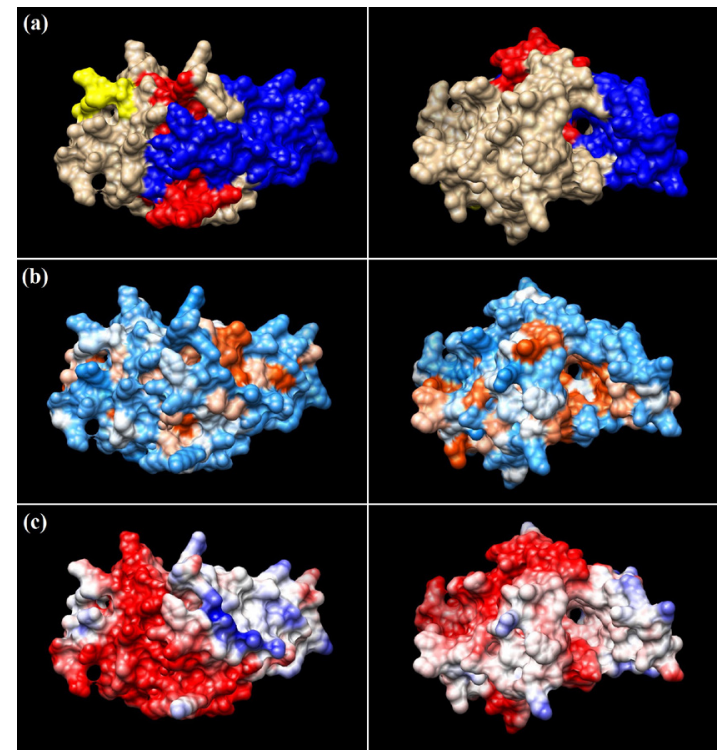

Figure 6. Tertiary structure prediction of MeTCTP. a. MBS, TCTP1 and TCTP2 regions are highlighted in blue, yellow and red respectively. b. Hydrophobicity represented as a color gradient, with blue being the most hydrophilic, to white, to orange red for the most hydrophobic. c. Electrostatic surface represented as a color gradient, from the most negatively charged (red) to the most positively charged (blue).

Genetics and Molecular Research 16 (3): gmr16039800 


\section{Conflicts of interest}

The authors declare no conflict of interest.

\section{ACKNOWLEDGMENTS}

Research supported by CAPES, and UFRPE resources. R.M. Moraes Filho was supported by a Post-Doctoral Fellowship PNPD-CAPES.

\section{REFERENCES}

Amzallag N, Passer BJ, Allanic D, Segura E, et al. (2004). TSAP6 facilitates the secretion of translationally controlled tumor protein/histamine releasing factor via a nonclassical pathway. J. Biol. Chem. 279: 104-112.

Arcuri F, Papa S, Carducci A, Romagnoli R, et al. (2004). Translationally controlled tumor protein (TCTP) in the human prostate and prostate cancer cells: expression, distribution, and calcium binding activity. Prostate 60: 130-140. https://doi.org/10.1002/pros.20054

Baum TJ, Hussey RS and Davis EL (2007). Root-knot and cyst nematode parasitism genes: the molecular basis of plant parasitism. In: Genetic Engineering, Vol. 28 (Setlow JK, ed.). 17-34. Springer Science Business Media, LLC, New York, USA.

Bird DM (2004). Signaling between nematodes and plants. Curr. Opin. Plant Biol. 7: 372-376.

Bommer UA and Thiele BJ (2004). The translationally controlled tumour protein (TCTP). Int. J. Biochem. Cell Biol. 36 : 379-385. https://doi.org/10.1016/S1357-2725(03)00213-9

Bonnet C, Perret E, Dumont X, Picard A, et al. (2000). Identification and transcription control of fission yeast genes repressed by an ammonium starvation growth arrest. Yeast 16: 23-33. https://doi.org/10.1002/(SICI)10970061(20000115)16:1<23::AID-YEA503>3.0.CO;2-A

Brown MP, Grundy WN, Lin D, Cristianini N, et al. (2000). Knowledge-based analysis of microarray gene expression data by using support vector machines. Proc. Natl. Acad. Sci. USA 97: 262-267. https://doi.org/10.1073/pnas.97.1.262

Chen VB, Davis IW and Richardson DC (2009). KING (Kinemage, Next Generation): a versatile interactive molecular and scientific visualization program. Protein Sci. 18: 2403-2409.

Chen VB, Arendall WB, 3rd, Headd JJ, Keedy DA, et al. (2010). MolProbity: all-atom structure validation for macromolecular crystallography. Acta Crystallogr. D Biol. Crystallogr. 66: 12-21. https://doi.org/10.1107/S0907444909042073

Chisholm ST, Coaker G, Day B and Staskawicz BJ (2006). Host-microbe interactions: shaping the evolution of the plant immune response. Cell 124: 803-814. https://doi.org/10.1016/j.cell.2006.02.008

Darabi M and Seddigh S (2015). Bioinformatic characterization of aspartic protease (AP) enzyme in seed plants. Plant Syst. Evol. 301: 2399-2417.

Davis EL, Hussey RS and Baum TJ (2004). Getting to the roots of parasitism by nematodes. Trends Parasitol. 20: 134-141. https://doi.org/10.1016/j.pt.2004.01.005

Davis EL, Hussey RS, Mitchum MG and Baum TJ (2008). Parasitism proteins in nematode-plant interactions. Curr. Opin. Plant Biol. 11: 360-366. https://doi.org/10.1016/j.pbi.2008.04.003

Franceschini A, Szklarczyk D, Frankild S, Kuhn M, et al. (2013). STRING v9.1: protein-protein interaction networks, with increased coverage and integration. Nucleic Acids Res. 41: D808-D815. https://doi.org/10.1093/nar/gks1094

Gachet Y, Tournier S, Lee M, Lazaris-Karatzas A, et al. (1999). The growth-related, translationally controlled protein P23 has properties of a tubulin binding protein and associates transiently with microtubules during the cell cycle. J. Cell Sci. 112: 1257-1271.

Gasteiger E, Hoogland C, Gattiker A, Duvaud S, et al. (2005). Protein identification and analysis tools on the ExPASy server. In: The proteomics protocols handbook (Walker JM, ed.). Humana Press, New York, 571-607.

Gnanasekar M, Rao KVN, Chen L, Narayanan RB, et al. (2002). Molecular characterization of a calcium binding translationally controlled tumor protein homologue from the filarial parasites Brugia malayi and Wuchereria bancrofti. Mol. Biochem. Parasitol. 121: 107-118. https://doi.org/10.1016/S0166-6851(02)00027-0

Gross B, Gaestel M, Böhm H and Bielka H (1989). cDNA sequence coding for a translationally controlled human tumor protein. Nucleic Acids Res. 17: 8367. https://doi.org/10.1093/nar/17.20.8367

Haegeman A, Vanholme B and Gheysen G (2009). Characterization of a putative endoxylanase in the migratory plantparasitic nematode Radopholus similis. Mol Plant Pathol. 10: 389-401.

Haegeman A, Mantelin S, Jones JT and Gheysen G (2012). Functional roles of effectors of plant-parasitic nematodes. Gene 492: 19-31. https://doi.org/10.1016/j.gene.2011.10.040

Genetics and Molecular Research 16 (3): gmr16039800 
Heath MC (2000). Hypersensitive response-related death. Plant Mol. Biol. 44: 321-334. https://doi. org/10.1023/A:1026592509060

Hoepflinger MC, Reitsamer J, Geretschlaeger AM, Mehlmer N, et al. (2013). The effect of translationally controlled tumour protein (TCTP) on programmed cell death in plants. BMC Plant Biol. 13: 135. https://doi.org/10.1186/1471-2229-13-135

Hussey R, Davis E and Baum T (2002). Secrets in secretions: genes that control nematode parasitism of plants. Braz. J. Plant Physiol. 14: 183-194. https://doi.org/10.1590/S1677-04202002000300002

Jefferys BR, Kelley LA and Sternberg MJ (2010). Protein folding requires crowd control in a simulated cell. J. Mol. Biol. 397: 1329-1338. https://doi.org/10.1016/j.jmb.2010.01.074

Jones JDG and Dangl JL (2006). The plant immune system. Nature 444: 323-329. https://doi.org/10.1038/nature05286

Koziol MJ and Gurdon JB (2012). TCTP in development and cancer. Biochem Res Int. Article ID 105203.

Kelley LA, Mezulis S, Yates CM, Wass MN, et al. (2015). The Phyre2 web portal for protein modeling, prediction and analysis. Nat. Protoc. 10: 845-858. https://doi.org/10.1038/nprot.2015.053

Langdon JM, Vonakis BM and MacDonald SM (2004). Identification of the interaction between the human recombinant histamine releasing factor/translationally controlled tumor protein and elongation factor-1 delta (also known as eElongation factor-1B beta). Biochim. Biophys. Acta 1688: 232-236. https://doi.org/10.1016/j.bbadis.2003.12.007

Le Sourd F, Boulben S, Le Bouffant R, Cormier P, et al. (2006). eEF1B: At the dawn of the 21st century. Biochim. Biophys. Acta 1759: 13-31.

Moraes Filho RM and Martins LSS (2016). In silico comparative analysis of tylenchid nematode pectate lyases. Genet. Mol. Res. 15: gmr.15038402.

Perry RN and Moens N (2011). Introduction to plant-parasitic nematodes: modes of parasitism. In: Genomics and molecular genetics of plant-nematode interactions (Jones J, Gheysen G and Fenoll C, eds.). Springer Science + Business Media, Dordrecht, 3-20.

Pettersen EF, Goddard TD, Huang CC, Couch GS, et al. (2004). UCSF Chimera - a visualization system for exploratory research and analysis. J. Comput. Chem. 25: 1605-1612. https://doi.org/10.1002/jcc.20084

Rai KM, Balasubramanian VK, Welker CM, Pang M, et al. (2015). Genome wide comprehensive analysis and web resource development on cell wall degrading enzymes from phyto-parasitic nematodes. BMC Plant Biol. 15: 187. https://doi.org/10.1186/s12870-015-0576-4

Rao KVN, Chen L, Gnanasekar M, Ramaswamy K (2002). Cloning and characterization of a calcium-binding, histaminereleasing protein from Schistosoma mansoni. J. Biol. Chem. 277: 31 207-31 213.

Sasikumar AN, Perez WB and Kinzy TG (2012). The many roles of the eukaryotic elongation factor 1 complex. Wiley Interdiscip. Rev. RNA 3: 543-555.

Shaw KL, Grimsley GR, Yakovlev GI, Makarov AA, et al. (2001). The effect of net charge on the solubility, activity, and stability of ribonuclease Sa. Protein Sci. 10: 1206-1215. https://doi.org/10.1110/ps.440101

Söding J (2005). Protein homology detection by HMM-HMM comparison. Bioinformatics 21: 951-960. https://doi. org/10.1093/bioinformatics/bti125

Tamura K, Peterson D, Peterson N, Stecher G, et al. (2011). MEGA5: molecular evolutionary genetics analysis using maximum likelihood, evolutionary distance, and maximum parsimony methods. Mol. Biol. Evol. 28: 2731-2739. https://doi.org/10.1093/molbev/msr121

Tsirigos KD, Peters C, Shu N, Käll L, et al. (2015). The TOPCONS web server for combined membrane protein topology and signal peptide prediction. Nucleic Acids Res. 43: 401-407. https://doi.org/10.1093/nar/gkv485

Vatansever R, Filiz E and Ozyigit II (2015). In silico identification and comparative analysis of molybdenum (Mo) transporter genes in plants. Braz. J. Bot. 39: 1-13.

Wiederstein M and Sippl MJ (2007). ProSA-web: interactive web service for the recognition of errors in three-dimensional structures of proteins. Nucleic Acids Res. 35: W407-10. https://doi.org/10.1093/nar/gkm290

Williamson VM and Gleason CA (2003). Plant-nematode interactions. Curr. Opin. Plant Biol. 6: 327-333. https://doi. org/10.1016/S1369-5266(03)00059-1

Wu HW, Gong WB, Yao XZ, Wang JF, et al. (2015). Evolutionarily Conserved Binding of Translationally Controlled Tumor Protein to Eukaryotic Elongation Factor 1B. J. Biol. Chem. 290: 8694-8710

Yenofsky R, Bergmann I and Brawerman G (1982). Messenger RNA species partially in a repressed state in mouse sarcoma ascites cells. Proc. Natl. Acad. Sci. USA 79: 5876-5880. https://doi.org/10.1073/pnas.79.19.5876

Yu CS, Cheng CW, Su WC, Chang KC, et al. (2014). CELLO2GO: a web server for protein subCELlular LOcalization prediction with functional gene ontology annotation. PLoS One 9: e99368. https://doi.org/10.1371/journal.pone.0099368

Zhuo K, Chen J, Lin B, Wang J, et al. (2016). A novel Meloidogyne enterolobii effector MeTCTP promotes parasitism by suppressing programmed cell death in host plants. Mol. Plant Pathol. 18: 45-54.

Genetics and Molecular Research 16 (3): gmr16039800 